\title{
Exertional Heat Stroke in Athletes
}

\author{
Metodija Kjertakov ${ }^{1 *}$, Yoram Epstein ${ }^{2,3}$ \\ ${ }^{1}$ Special Operations Regiment, Army of Republic of Macedonia, Skopje, Republic of Macedonia; ${ }^{2}$ Heller Institute of Medical \\ Research, Sheba Medical Center, Tel Hashomer, Israel; ${ }^{3}$ The Sackler Faculty of Medicine, Tel Aviv University, Israel
}

\begin{abstract}
Citation: Kjertakov M, Epstein Y. Exertiona Heat Stroke in Athletes. OA Maced J Med Sci. $2013 \quad$ Dec 15; 1(1):135

Key words: exertional heat stroke; heat illness; heat stress; thermoregulation; hyperthermia.

"Correspondence: Mr. Metodija Kjertakov. V S Bato $75-3 / 46$, Skopje 1000, Republic of Macedonia.

M-Mail: metodijakertakov@yahoo.com

Received: 06-May-2013; Revised: 21-Jul2013; Accepted: 22-Jul-2013; Online first: 25-Sep-2013

Copyright: () 2013 Kjertakov M. This is an open-access article distributed under the terms of the Creative Commons Attribution License which permits unrestricted use, distribution, and reproduction in any medium, provided the original author and source are credited.

Competing Interests: The authors have declared that no competing interests exist.
\end{abstract}

\begin{abstract}
Exercising in hot and especially humid environment can cause rise in body core temperature to such a critical level that it does not only reduce performance, but also may ultimately lead to exertional heat stroke (EHS). This illness is true medical emergency that can result in significant morbidity and mortality, if not early recognized and promptly treated. Diagnostic criteria for EHS are body core temperature above $40^{\circ} \mathrm{C}$ and central nerve system dysfunction. Any athlete experiencing such symptoms should be immediately exposed to aggressive cooling treatment aimed to lower the elevated core temperature to near normal as quickly as possible. Ice water immersion is highly recommended as a cooling method because it provides the fastest cooling rates and is associated with lowest mortality rates. Athletes cooled rapidly soon after the onset of EHS usually recover without complications and are able to return to normal training in hot environment within a few weeks. EHS is also a preventable condition, and its occurrence can be minimized by implementing a few simple measures.
\end{abstract}

\section{Introduction}

The human body is equipped with well developed thermoregulation mechanisms that regulate its internal temperature at about $37^{\circ} \mathrm{C}$ for optimal function of organ systems. Nevertheless, it is not uncommon for athletes who train and compete in hot and humid environment to experience thermoregulation problems with the consequences ranging from premature fatigue to serious heat illness, such as exertional heat stroke (EHS) [1, 2]. This illness is a true medical emergency that can result in significant morbidity and mortality, if not early recognized and promptly treated [3-6]. In fact, EHS is reported to be the third leading cause of death among athletes [7], with American-type football players and distance runners being the most commonly affected [3]. Considering this, and especially since we are experiencing a period of global warming which can be expected to increase the incidence of EHS, education in recognition, treatment and prevention of this illness is essential, if heat-related deaths in athletic fields are to be avoided in the future.

\section{Definition of Heat-Related IIInesses}

In general, heat exposure can result in a variety of heat disorders including heat edema, heat syncope, heat cramps, heat exhaustion and heat stroke [8-10]. Heat edema is the mildest form of heat illness, which appears as a swelling of hands and feet, usually in unacclimatized individuals. Heat syncope is fainting that is usually associated with prolonged standing or sudden rising from a lying position. Heat cramps are involuntary, painful, spasmodic contractions of muscles, which tend to occur in settings of heavy sweating coupled with inadequate fluid and sodium intake [11, 12]. Heat exhaustion is the most common form of heat illness defined as the inability to continue the activity in the heat [13]. It is caused by the inability of the body to sustain the rate of cardiac output necessary to simultaneously meet the demands of blood flow for exercising muscle, skin and vital organs. Dehydration-induced plasma volume depletion is thought to be the primary factor for the development of this condition [11, 13]. Heat stroke, defined by a body core temperature above $40^{\circ} \mathrm{C}$ and central nerve system dysfunction, occurs when body's 
thermoregulation system fails to remove the excess heat accumulated from metabolic processes and external environment [13-15]. Traditionally, heat stroke has been described in two forms: classic heat stroke (CHS) and exertional heat stroke (EHS). CHS occurs during the summer heat waves, affecting primarily the vulnerable population such as elderly, young children, those with pre-existing diseases, alcoholics, and drug abusers, while the EHS occurs in previously healthy young individuals involved in strenuous physical activities, usually in the heat.

\section{Thermoregulation}

During intense exercise, athlete's metabolic rate can increase 15-20 times above resting level. However, only $20-25 \%$ of the energy produced is used for muscle work, with the remaining $75-80 \%$ released as heat. As a consequence of this process body heat content might be markedly increased. To prevent elevation of core temperature to dangerous level most of the generated heat must be transferred from body's core to the skin surface via circulatory system, and subsequently dissipated to the surrounding environment by means of radiation, convection, conduction and evaporation [9]. Radiation is direct transfer of heat from body into the environment by infrared waves. Convection involves heat loss by air circulating around the body. Conduction refers to heat loss by direct contact with a cooler surface. Evaporation is dissipation of heat through vaporization of sweat from the skin surface.

Of these four heat dissipation mechanisms, the most important during exercise in the heat is evaporation of sweat. In fact, on a hot day, when the temperature of the air exceeds that of the skin surface, evaporation becomes the only heat loss avenue available $[9,16]$. However, the ability to dissipate heat through sweating is determined by the water vapor pressure gradient between the skin and the air. At a given ambient temperature when the relative humidity of the air is low, the water vapor pressure gradient between the skin and the air will be large and sweat will evaporate relatively fast, enabling efficient body cooling. High relative humidity at the same ambient temperature, on the other hand, creates lower vapor pressure gradient between the skin and the air which impairs evaporation of sweat from the skin $[4,16]$. Thus, although an athlete may experience profuse sweating, a large percent of the sweat will merely drip off the body without any heat loss. At this point, therefore, body's ability to thermoregulate effectively will be significantly compromised. Consequently, exercising under these environmental conditions may result in body heat production in excess of heat loss, a situation which if persists for sufficient period of time can cause core temperature to reach such a critical level that it does not only reduce performance, but also may ultimately lead to EHS [1, 2, 9, 17].

\section{Predisposing factors for EHS}

Although EHS poses a threat to virtually all athletes exercising in the heat, it appears that certain athletes are particularly at risk of becoming heat casualties. Those are athletes who have some medical or physiological condition that can provoke heat intolerance [18, 19]. A comprehensive list of predisposing factors for EHS is shown in Table 1. These factors exert their negative effects mainly through disruption of body's thermoregulation by either impairing heat dissipation process or increasing endogenous heat production [17].

Table 1: Predisposing factors for EHS.

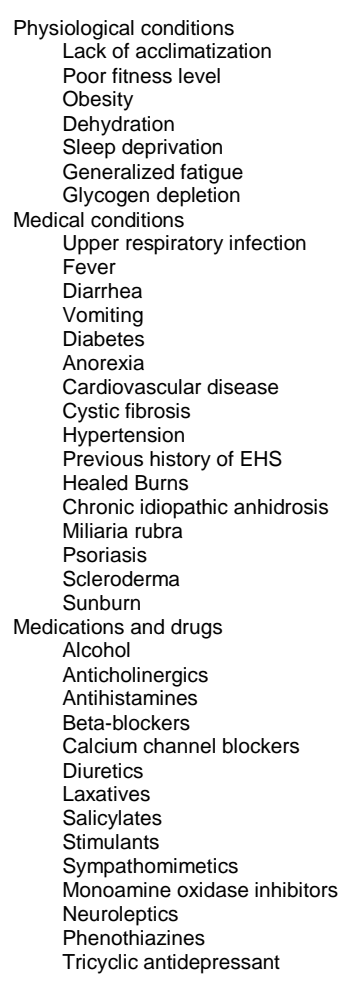

Lack of heat acclimation, poor fitness level, obesity, dehydration and current or recent illness are considered to be the most significant predisposing factors for EHS [18, 20]. Sleep loss and generalized fatigue are acknowledged as predisposing factors, and have been implicated in several EHS cases [21]. Skin disorders can seriously compromise evaporative heat loss because of the diminished ability of sweat glands for sweat secretion, and thus lead to EHS [22]. Prior EHS injury can cause heat intolerance for a variable period of time after an incident, and as a result it may increase the risk for recurrence of this illness [4, 23, 24]. Various types of drugs and medications can also contribute to the development of dangerous hyperthermia $[5,7,13]$. Notably, commonly used performance enhancing substance Ephedra has been associated with a number of adverse health 
events, one of which is EHS [25].

\section{Recognition of EHS}

Any change in athletes' mental status such as confusion, inappropriate behavior or impaired judgment during or shortly after exercise in the heat may indicate the presence of EHS [3, 6, 7], as the brain is especially sensitive to hyperthermia [11]. However, in majority of the cases the onset of EHS is accompanied by a physical collapse and manifestations of central nervous system dysfunction ranging from disorientation to delirium and coma [6, $16,26,27]$. Other common signs and symptoms include profuse sweating, tachycardia, hyperventilation, hypotension, convulsion, dehydration, vomiting and diarrhea $[1,3,6]$.

To confirm the diagnosis of EHS, core temperature must be measured as soon as possible post-incident, and this has to be done via the rectal route [1, 3-7, 26-28]. Skin, oral, aural and axillary routes do not accurately reflect core temperature under the field settings [29, 30], and therefore they should never be used when evaluating the athlete suspected to have suffered from EHS [3]. Rectal temperature reading above $40^{\circ} \mathrm{C}$ coupled with altered mental status is accepted as diagnostic criteria for EHS [3-7, 27, 31].

Table 2: Differential diagnosis of EHS.

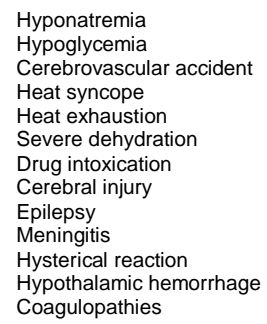

Apart from EHS, there are a few other medical conditions (Table 2) that can also cause athlete to collapse or present with changes in mental status [1, 7, 26-28], but none of these are associated with extreme hyperthermia, and as such they can be distinguished from EHS by a rectal temperature $<40^{\circ} \mathrm{C}$. For instance, one such condition that can be initially mistaken for EHS is hyponatremia of exercise [31-33], which is defined as a serum sodium concentration less than $130 \mathrm{mmol} / \mathrm{L}$, and occurs most commonly during the marathon races and ultraendurance-type events [34]. Misdiagnosis of EHS will result in improper management, which in turn increases the likelihood of a tragic outcome [35].

\section{Treatment of EHS}

Once a diagnosis of EHS has been established treatment must follow immediately, focusing on whole-body cooling. Lowering the core temperature to near normal as quickly as possible is crucial, because the damage caused by EHS is directly related to the magnitude and duration of hyperthermia [5, 7, 28, 36, 37]. Thus, for the best medical outcome and in the absence of other lifethreatening complications, it is recommended cooling to be achieved on-site prior transferring the athlete to a medical facility $[3,5,26]$.

Initially, the affected athlete should be moved in the shade or cooler area and get undressed while preparing for cooling to be initiated. Several wholebody cooling methods have been described in the literature and much debate exists regarding which one is the most effective as well as practical to be employed in the treatment of heat stroke [16, 36, 38]. Nevertheless, so far, the most rapid cooling and the lowest mortality rates have been observed with cold and ice water immersion [1, 3-5, 39]. In the athletic field, this can be done by immersing the athlete's torso and upper legs in a small plastic tub or pool filled with water and ice [40]. In this way, a cooling rate of $0.20^{\circ} \mathrm{C} / \mathrm{min}$ can be achieved, resulting in lowering the core temperature below $39^{\circ} \mathrm{C}$ within $10-40$ minutes [41]. Alternatively, when water immersion is not feasible, athlete should be treated with rapid rotation of ice water soaked towels or by dousing a large amount of tap water on the skin combined with fanning. These forms of cooling have also been shown to be very effective, providing a cooling power comparable to that of water immersion [6, 42]. Along with the cooling treatment $500-1000 \mathrm{ml}$ of intravenous fluid of normal saline should be given [1]. Cooling should be discontinued when core temperature falls to $38^{\circ} \mathrm{C}$ or the athlete begins to shiver, to prevent hypothermia [1, 4, 27, 28]. Following the initial treatment athlete must immediately be transferred to the appropriate medical facility for further evaluation and monitoring.

\section{Recovery from EHS and return to training}

Following an episode of EHS, even with a timely treatment, athlete may experience some organ damage and temporary heat intolerance, which as has been mentioned above, may increase the risk for subsequent EHS incident [4, 23, 24]. Thus, it is essential to ensure that full recovery from EHS takes place before athlete returns to normal training in hot environment [5]. For that purpose, the following guidelines [1, 3, 5, 24, 43] are recommended. First, it is advised that no exercise should take place for at least 1 week following post-hospital treatment, after which athlete should undergo full medical examination. Second, once asymptomatic and all laboratory tests have normalized, athlete may begin exercising in climate-controlled environment while being closely monitored for potential signs and symptoms of heat illness. Over the course of next 2 
weeks the intensity and duration of training sessions as well as heat exposure should be gradually increased in order to re-establish heat acclimatization and fitness level. Third, about 3 to 4 weeks after the EHS episode, athlete should undergo heat tolerance test to assess his/her heat tolerance ability. If the test results are normal, athlete can be cleared for exercising without restriction; otherwise the test should be repeated 4 to 8 weeks later. In general, athletes cooled rapidly soon after the collapse, usually recover completely within a few weeks [5].

\section{Prevention of EHS}

The risk of EHS in hot weather can be reduced by scheduling the sporting events during the early morning or evening to avoid the hottest hours of the day. In addition, it is important that athlete is well rested and adequately nourished prior to event and avoids heavy exertion until he/she becomes acclimatized to the surrounding environment. Achieving heat acclimatization, which usually requires 10-14 days of moderate exercise in the heat, is crucial as it helps to counteract the adverse effects of heat stress $[3,4]$. Yet this does not make athlete immune to EHS, especially when exercising under the conditions of severe heat and high humidity. In such cases, lowering the exercise intensity, increasing the number or duration of rest breaks and frequently changing the players in team sports are effective measures to limit the body heat gain. Pre-cooling and proper hydration are other strategies that can also provide some protection against hyperthermia by reducing the rate of core temperature elevation [4446]. Similarly, exercising in clothing that is made of lightweight, breathable and light-colored material allows efficient elimination of heat from the body and reduces solar heat load [9]. Finally, athletes who experience some of the predisposing factors listed in Table 1 should not take part in strenuous exercises.

\section{Conclusion}

Exercising in hot and especially humid environment places unusual demand on the mechanisms that regulate body temperature and significantly increase the risk for EHS. Thus, whenever a sporting event is planned to take place under such environmental conditions, adequate measures must be taken to prevent EHS from occurring, and if it does occur, to avoid serious injury and death. Early recognition and rapid cooling are the key factors for a satisfactory outcome.

\section{References}

1. Casa DJ, Armstrong LE. Exertional heatstroke: a medical emergency. In: Armstrong LE, editor. Exertional Heat Illnesses. Champaign, IL: Human Kinetics. 2003:29-56.
2. Simon HB. Hyperthermia. N Engl J Med. 1993;329(7):483-7.

3. Armstrong LE, Casa DJ, Millard-Stafford M, Moran DS, Pyne SW, Roberts WO. American College of Sports Medicine position stand. Exertional heat illness during training and competition. Med Sci Sports Exerc. 2007;39(3):556-72.

4. Binkley HM, Beckett J, Casa DJ, Kleiner DM, Plummer PE. National Athletic Trainers' Association Position Statement: Exertional Heat Illnesses. J Athl Train. 2002;37(3):329-343.

5. Casa DJ, Armstrong LE, Kenny GP, O'Connor FG, Huggins RA. Exertional heat stroke: new concepts regarding cause and care. Curr Sports Med Rep. 2012;11(3):115-23.

6. Roberts WO. Exertional heat stroke: life-saving recognition and onsite treatment in athletic settings. Rev Bras Med Esporte. 2005;11(6):329-31.

7. Howe AS, Boden BP. Heat-related illness in athletes. Am J Sports Med. 2007;35(8):1384-95.

8. Barrow MW, Clark KA. Heat-related illnesses. Am Fam Physician. 1998;58(3):749-56.

9. Coris EE, Ramirez AM, Van Durme DJ. Heat illness in athletes: the dangerous combination of heat, humidity and exercise. Sports Med. 2004;34(1):9-16.

10. Lugo-Amador NM, Rothenhaus T, Moyer P. Heat-related illness. Emerg Med Clin North Am. 2004;22(2):315-27.

11. Hubbard RW, Armstrong LE. The heat illness: biochemical, ultrastructural, and fluid-electrolyte considerations. In: Pandolf KB, Sawka MN, Gonzalez RR, editors. Human Performance Physiology and Environment Medicine at Terrestrial Extremes. Indianapolis. Benchmark Press; 1988:305-359.

12. Bergeron MF. Heat cramps during tennis: a case report. Int $J$ Sport Nutr. 1996;6(1):62-8.

13. Knochel JP. Heat stroke and related heat stress disorders. Dis Mon. 1989;35(5):301-77.

14. Bouchama A, Knochel JP. Heat stroke. N Engl J Med. 2002;346(25):1978-88.

15. Yeo TP. Heat stroke: a comprehensive review. AACN Clin Issues. 2004;15(2):280-93.

16. Yaqub B, Al Deeb S. Heat stroke: aetiopathogenesis, neurological characteristics, treatment and outcome. J Neurol Sci. 1998;156(2):144-51.

17. Brewster SJ, O'Connor FG, Lillegard WA. Exercise-induced heat injury: diagnosis and management. Sports Med Arthrosc. 1995;3(4):260-6.

18. Cleary $M$. Predisposing risk factors on susceptibility to exertional heat illness: clinical decision-making considerations. J Sport Rehabil. 2007;16(3):204-14.

19. Epstein Y. Heat intolerance: predisposing factor or residual injury? Med Sci Sports Exerc. 1990;22(1):29-35.

20. Epstein Y, Moran DS, Shapiro Y, Sohar E, Shemer J. Exertional heat stroke: a case series. Med Sci Sports Exerc. 1999;31(2):224-8.

21. Armstrong LE, De Luca JP, Hubbard RW. Time course of recovery and heat acclimation ability of prior exertional heatstroke patients. Med Sci Sports Exerc. 1990;22(1):36-48.

22. Seth $\mathrm{P}$, Juliana $\mathrm{P}$. Exertional heat stroke in a marathon runner with extensive healed deep burns: a case report. Int J Emerg Med. 2011;4:12.

23. Casa DJ. Don't gamble: complex considerations regarding return to play following exertional heat stroke. J Sport Rehabil. 2007;16(3):161-2.

24. McDermott BP, Casa DJ, Yeargin SW, Ganio MS, Armstrong LE, Maresh CM. Recovery and return to activity following exertional heat stroke: considerations for the sports medicine 
staff. J Sport Rehabil. 2007;16(3):163-81.

25. Oh RC, Henning JS. Exertional heatstroke in an infantry soldier taking ephedra-containing dietary supplements. Mil Med. 2003;168(6):429-30.

26. Roberts WO. Managing heatstroke: on-site cooling. Phys Sportsmed. 1992;20(5):17-28.

27. Sandor RP. Heat illness: on-site diagnosis and cooling. Phys Sportsmed. 1997;25(6):35-40.

28. Shapiro $Y$, Seidman DS. Field and clinical observations of exertional heat stroke patients. Med Sci Sports Exerc. 1990;22(1):6-14

29. Casa DJ, Becker SM, Ganio MS, Brown CM, Yeargin SW, Roti MW, Siegler J, Blowers JA, Glaviano NR, Huggins RA Armstrong LE, Maresh CM. Validity of devices that assess body temperature during outdoor exercise in the heat. J Athl Train. 2007;42(3):333-42.

30. Roth RN, Verdile VP, Grollman LJ, Stone DA. Agreement between rectal and tympanic membrane temperatures in marathon runners. Ann Emerg Med. 1996;28(4):414-7.

31. Holtzhausen LM, Noakes TD. Collapsed ultraendurance athlete: proposed mechanisms and an approach to management. Clin J Sport Med. 1997;7(4):292-301.

32. Blue JG, Pecci MA. The collapsed athlete. Orthop Clin North Am. 2002;33(3):471-8.

33. Garigan TP, Ristedt DE. Death from hyponatremia as a result of acute water intoxication in an Army basic trainee. Mil Med. 1999;164(3):234-8.

34. Armstrong LE. Exertional hyponatremia. In: Armstrong LE, editor. Exertional Heat Illnesses. Champaign, IL: Human Kinetics; 2003:103-135

35. Assia E, Epstein $Y$, Shapiro $Y$. Fatal heatstroke after a short march at night: a case report. Aviat Space Environ Med. 1985;56(5):441-2.

36. Hadad E, Rav-Acha M, Heled Y, Epstein Y, Moran DS. Heat stroke: a review of cooling methods. Sports Med. 2004;34(8):501-11.

37. Shapiro $\mathrm{Y}$, Rosenthal T, Sohar E. Experimental heatstroke. A model in dogs. Arch Intern Med. 1973;131(5):688-92.

38. Harker J, Gibson P. Heat-stroke: a review of rapid cooling techniques. Intensive Crit Care Nurs. 1995;11(4):198-202.

39. Costrini A. Emergency treatment of exertional heatstroke and comparison of whole body cooling techniques. Med Sci Sports Exerc. 1990;22(1):15-8.

40. Roberts WO. Tub cooling for exertional heatstroke. Phys Sportsmed. 1998;26(5):111-2.

41. Armstrong LE, Crago AE, Adams R, Roberts WO, Maresh CM. Whole-body cooling of hyperthermic runners: comparison of two field therapies. Am J Emerg Med. 1996;14(4):355-8.

42. Hadad E, Moran DS, Epstein Y. Cooling heat stroke patients by available field measures. Intensive Care Med. 2004;30(2):338

43. Moran DS, Erlich T, Epstein Y. The heat tolerance test: an efficient screening tool for evaluating susceptibility to heat. J Sport Rehabil. 2007;16(3):215-21.

44. Hargreaves M, Febbraio M. Limits to exercise performance in the heat. Int J Sports Med. 1998;19 Suppl 2:S115-6.

45. Hargreaves M. Physiological limits to exercise performance in the heat. J Sci Med Sport. 2008;11(1):66-71.

46. Hasegawa $\mathrm{H}$, Takatori $\mathrm{T}$, Komura $\mathrm{T}$, Yamasaki M. Combined effects of pre-cooling and water ingestion on thermoregulation and physical capacity during exercise in a hot environment. $J$ Sports Sci. 2006;24(1):3-9. 